\title{
Recent Progress in Plasma Control Studies on the Improvement of Plasma Performance in Heliotron J
}

\section{$\operatorname{AUTHOR}(\mathrm{S}):$}

Mizuuchi, Tohru; Nagasaki, Kazunobu; Okada, Hiroyuki; Kobayashi, Shinji; Yamamoto, Satoshi; Minami, Takashi; Ohshima, Shinsuke; ... Nakamura, Yuji; Konoshima, Shigeru; Sano, Fumimichi

\section{CITATION:}

Mizuuchi, Tohru ...[et al]. Recent Progress in Plasma Control Studies on the Improvement of Plasma Performance in Heliotron J. Plasma Science and Technology 2011, 13(1): 21-25

\section{ISSUE DATE:}

2011-02-01

URL:

http://hdl.handle.net/2433/139479

\section{RIGHT:}

(C) IOP Publishing 2011; この論文は出版社版でありません。引用の際に は出版社版をご確認ご利用ください。; This is not the published version. Please cite only the published version. 


\title{
Recent Progress on Plasma Control Studies to Improve Plasma Performance in Heliotron $\mathbf{J}$
}

MIZUUCHI Tohru ${ }^{1}$, NAGASAKI Kazunobu ${ }^{1}$, OKADA Hiroyuki ${ }^{1}$, KOBAYASHI Shinji ${ }^{1}$,YAMAMOTO Satoshi ${ }^{1}$, MINAMI Takashi ${ }^{1}$, OHSHIMA Shinsuke ${ }^{2}$, TAKEUCHI Masaki ${ }^{1}$, MUKAI Kiyofumi ${ }^{3}$, LEE Hyunyong ${ }^{3}$, ZANG Linge ${ }^{3}$, NOMURA Kohta ${ }^{3}$, SUWA Masashige ${ }^{3}$, YAMAMOTO Kento ${ }^{3}$, YASHIRO Hiroaki ${ }^{3}$, YOSHINO Hayao ${ }^{3}$, ARAI Shouhei ${ }^{3}$, KAGAWA Tasuku ${ }^{3}$, MINAMI Takayuki ${ }^{3}$, MIZUNO Kouji ${ }^{3}$, WADA Yoshinobu ${ }^{3}$, WATADA Hiroto ${ }^{3}$, NISHINO Nobuhiro ${ }^{4}$, NAKASHIMA Yosuke ${ }^{5}$, HANATANI Kiyoshi ${ }^{1}$, NAKAMURA Yuji ${ }^{3}$, KONOSHIMA Shigeru $^{1}$ and SANO Fumimichi ${ }^{1}$

${ }^{1}$ Institute of Advanced Energy, Kyoto Univ., Gokasho, Uji, 611-0011 Japan. ${ }^{2}$ Kyoto Univ. Pioneering Research Unit for Next Generation, Gokasho, Uji, Japan. ${ }^{3}$ Graduate School of Energy Science, Kyoto Univ., Gokasho, Uji, Japan.

${ }^{4}$ Graduate School of Engineering, Hiroshima Univ., Higashi-Hiroshima, Japan. ${ }^{5}$ Plasma Research Center, Univ. of Tsukuba, Tsukuba, Japan.

\begin{abstract}
This paper reviews recent progress on plasma control studies to improve plasma performance in Heliotron J. The SMBI fueling is successfully applied to Heliotron J plasma. A supersonic $\mathrm{H}_{2}$-beam is effective to increase fueling efficiency and make a peaked density profile. Local fueling with a short pulse by SMBI can increase the core plasma density avoiding the degradation due to the edge cooling. Second harmonic ECCD experiments have been performed by injecting a focused Gaussian beam with a parallel refractive index of $-0.05 \leq N_{\|} \leq 0.6$. The experimental results show that the electron cyclotron (EC) driven current is determined not only by $N_{\|}$but also by local magnetic field $(B)$ structure where the EC power is deposited. The detailed analysis of the observed $\boldsymbol{N}_{\|}$and $B$ dependences is in progress with a ray-tracing simulation using TRAVIS code. Fast ion velocity distribution has been investigated using fast protons generated by ICRF minority heating. In the standard configuration in Heliotron J, CX-NPA measurements show the higher effective temperature of fast minority protons in the on-axis resonance case than that in the HFS (high field side) off-axis resonance case. However, the increase of the bulk ion temperature in the HFS resonance case is larger than that in the on-axis resonance.
\end{abstract}

Keywords: plasma control, Heliotron J, improved confinement, ECH/ECCD, NBI, ICRF, minority heating, 
fueling control.

PACS: $52.20 . \mathrm{Hv}, 52.25 . Y a, 52.55 .-\mathrm{s}, 52.50 .-\mathrm{b}, 52.30 .-\mathrm{q}$, 52.75.-d, 52.35.Hr, 52.35.Qz

\section{Introduction}

Heliotron $\mathrm{J}^{[1,2]}$ is a medium sized helical device $\left(\left\langle R_{0}\right\rangle /\left\langle a_{\mathrm{p}}\right\rangle=1.2 / 0.17 \mathrm{~m},\left\langle B_{0}\right\rangle \leq 1.5 \mathrm{~T}\right)$ based on the helical-axis heliotron concept ${ }^{[3,4]}$ with an $L / M=1 / 4$ helical coil. Here, $L$ and $M$ are the pole number of the helical coil and its helical pitch number, respectively. In the helical-axis heliotron concept, the bumpiness $\varepsilon_{\mathrm{b}}$ is introduced as the third measure to control the neoclassical transport in addition to the other major harmonics in the Boozer coordinates, helicity $\varepsilon_{\mathrm{h}}$ and toroidicity $\varepsilon_{\mathrm{t}}$. One of the main goals of the Heliotron J project is to experimentally explore the potential of this advanced concept as an attractive fusion device and to expand the operation regimes of the helical system.

In the previous experiments, the configuration effects on various aspects of plasma performance (bulk plasma confinement, high-energy particle confinement, plasma current control, particle fuelling, magnet-hydro-dynamics (MHD), etc.) were mainly investigated in the parameter range of $\left(1 / 2 \pi, \varepsilon_{b}\right){ }^{[5]}$. Recently, experiments in the expanded investigation range in $\left(\varepsilon_{t} / \varepsilon_{\mathrm{h}}\right.$, $\varepsilon_{\mathrm{b}} / \varepsilon_{\mathrm{h}}$ )-space have been performed. In addition to such configuration studies, survey of effective heating and fuelling scenarios has been conducted for better plasma performance. By using ICRF minority heating, the fast ion formation and confinement has been investigated under low-density conditions $\left(\sim 4 \times 10^{18} \mathrm{~m}^{-3}\right)$ by changing the resonance position. The ECCD experiments have been carried out by controlling a parallel refractive index $\left(N_{\|}\right)$at several conditions of the magnetic field ripple. These results are compared with expectations from numerical simulations. The $\mathrm{NBI}$ (neutral beam injection) experiments with two tangential beam lines (Co and CTR) have been performed not only to control plasma performance in higher density region but also to study high-energy particle loss mechanism and relating MHD phenomena in a helical-axis heliotron. The optimization of fuelling scenario is also in progress. A gas fuelling by supersonic molecular beam injection (SMBI) was successively applied to $\mathrm{ECH}$ (electron cyclotron heating)/NBI plasmas ${ }^{[6]}$. An interesting discharge mode, similar to the re-heat mode in CHS ${ }^{[7]}$, is observed for high power NBI with short-pulse intensive gas-puffing. 
This paper briefly reviews the recent progress on plasma control studies to improve plasma performance in Heliotron J.

\section{Experimental Set-up}

Figure 1 schematically shows a layout of main heating, fueling and some diagnostic equipment. The initial hydrogen or deuterium plasma is usually produced by using second harmonic X-mode ECH $(70 \mathrm{GHz},<0.40 \mathrm{MW})$. The hydrogen beam is injected for NBI experiments by using one or two tangential beam-lines (BL-1 and BL-2). The acceleration voltage of $\mathrm{NB}$ is $<30 \mathrm{kV}$ and the beam power is $<0.7 \mathrm{MW} /$ beam-line). For density control, a piezoelectric-valve system is usually used as a conventional gas-puffing (GP) system, which are installed at four inboard-side ports at $\approx 90^{\circ}$ intervals around the torus (indicated by "Gas" in Fig. 1). Due to the space limitation, the nozzles of these valves do not directly see the plasma. The amount of $\mathrm{H}$ (or D) atoms from the GP system is pre-programmed to control the line-averaged density $\bar{n}_{\mathrm{e}}$. Two SMBI systems of hydrogen are equipped on two horizontal outboard-side ports (the port number: \#3.5,\#11.5). The SMBI system at \#11.5 consists of a fast solenoid-valve with a short $(\sim 4 \mathrm{~mm})$ conic-nozzle. The diameter of its orifice is $0.2 \mathrm{~mm}^{\phi}$ for this experiment. To reduce the stray field effect on the fast valve action, a soft-magnetic-iron cylinder covers it as a magnetic shield. The other system at \#3.5 consists of a fast piezoelectric valve with a short conic-nozzle ( $0.2 \mathrm{~mm}^{\phi}$ orifice). In front of the \#3.5-SMBI nozzle, a movable shutter plate is installed to protect a viewing window at the same port. The amount of $\mathrm{H}$ atoms injected with these SMBIs is controlled by changing the pulse width of each SMBI valve under a fixed plenum pressure $\left(P_{\mathrm{pl}}\right.$ $\sim 1-2 \mathrm{MPa})$.

\section{Effects of SMBI Fueling}

Fueling and recycling control is one of the key issues to obtain high density and high performance plasma in magnetic confinement devices from two aspects; (1) profile control of core plasma and (2) reduction of neutrals in the peripheral region. A supersonic molecular-beam injection (SMBI) technique is considered to be not only an effective fueling method for deeper penetration of neutral particles into the core plasma compared to the conventional gas-puffing 
(GP) ${ }^{[8]}$ but also an effective edge modification technique in fusion devices ${ }^{[9,10,11]}$. In Heliotron J, fueling control studies have been performed with high-pressure SMBI. In a combination heating condition of $\mathrm{ECH}$ and $\mathrm{Co}-\mathrm{NBI}$, the stored energy reached $\sim 4.5 \mathrm{~kJ}$, which is about $50 \%$ higher than the maximum one achieved so far under the similar heating condition with conventional gas-puff fueling in Heliotron $\mathrm{J}^{[6]}$.

The speed of injected $\mathrm{H}_{2}$-beam is evaluated by a "time of flight" method, where the distance from the nozzle to the last closed flux surface (LCFS) is divided by the delay time from the SMBI trigger to the start of $\mathrm{H} \alpha$ increase monitored at almost the same toroidal position with the injector. The beam speed of 1.3-1.6 km/s is evaluated for $P_{\mathrm{pl}} \sim 1.0-1.5 \mathrm{MPa}^{[12]}$. Since the beam speed itself is not so fast compared to that for $\mathrm{H}_{2}$ introduced by normal GP (i.e. thermal speed at room temperature), a key of SMBI fueling, which cause the peculiar plasma performance in SMBI, should be the directional motion of the injected gas and the small area of plasma-beam interaction. If the high neutral density area is small enough and localized in SMBI, it could be useful to avoid the degradation of plasma performance through the increase of CX-loss, convection, etc.

Direct comparison between the directed (beam) gas injection and non-directional gas injection was performed by using the shutter plate in front of the \#3.5-SMBI nozzle. When the shutter is open, the injected beam can reach directly to the plasma, while the beam is blocked at the shutter and then the injected gas diffuses to the plasma when the shutter is closed. Figure 2 shows time traces of the stored energy $W_{\mathrm{p}}$ and the line-averaged density $\bar{n}_{\mathrm{e}}$ and the intensity of $\mathrm{H} \alpha$ emission at $\# 3.5$ (indicating the SMBI timing, $t \approx 208.5 \mathrm{~ms}$ ), $H_{\alpha}^{\# 3.5}$, for two discharges under the same experimental condition except for the shutter condition; the shutter is open (Fig. 2(a)) and closed (Fig. 2(b)). The SMBI timing is indicated by a rapid increase of $H_{\alpha}^{\# 3.5}$. As shown in Fig. 2(a), $\bar{n}_{\mathrm{e}}$ shows quick increase just after SMBI and then gradually increases up to $\sim 2.6 \times 10^{19} \mathrm{~m}^{-3}$ during $\sim 30 \mathrm{~ms}$ in the directly injected case (the open shutter case). The stored energy also shows rapid increase with a slight delay, keeps the elevated value for $\sim 10 \mathrm{~ms}$ and then starts to decrease when the increase of $\bar{n}_{\mathrm{e}}$ becomes saturated. In the case of closed shutter (Fig. 2(b)), on the other hand, the increases of $\bar{n}_{\mathrm{e}}$ and $W_{\mathrm{p}}$ are slow and mild. The density already saturates at $\sim 1.4 \times 10^{19} \mathrm{~m}^{-3}$ and starts to decrease at $\sim 15 \mathrm{~ms}$ after SMBI. The change of density 
profile for these two discharges is measured with a microwave reflectmeter ${ }^{[13]}$ at $\# 15.5$ section. In the open shutter case, the density profile, which is rather flat before SMBI, rapidly changes to a peaked one after SMBI, while the profile change is slow and mild in the closed shutter case ${ }^{[14]}$. These observations indicate that the injected beam well penetrates to core plasma region in the open shutter case. Since the amount of injected gas is the same for these two cases, the difference of the attainable $\bar{n}_{\mathrm{e}}$ after the SMBI indicates the effectiveness of "deep fueling" by SMBI in the fueling efficiency and/or the confinement improving.

\section{Second Harmonic Electron Cyclotron Current Drive}

In stellarators/heliotrons, non-inductive current can change the rotational transform profile, affecting equilibrium and MHD activities like in tokamaks. In a low magnetic shear configuration, moreover, non-inductive current also can modify the edge field topology and divertor performance ${ }^{[15]}$. Electron cyclotron current drive (ECCD) is expected as an effective method to control such non-inductive current effects caused by finite-plasma pressure and neutral beams.

The ECCD experiments in Heliotron $\mathrm{J}$ revealed strong dependence of the magnetic field configuration on the EC current (Fig. 3) ${ }^{[16,17]}$. (Figure.3) This suggests that the ECCD is determined by the balance between two current drive mechanisms; the Fisch-Boozer and the Ohkawa effects. To deepen understanding in the ECCD physics and to extend the controllability of ECCD in a helical-axis heliotron, a launching system with a focusing mirror and a steering mirror has been installed recently ${ }^{[18]}$. By using this system, a focused Gaussian beam is injected with the parallel refractive index of $-0.05 \leq N_{\|} \leq 0.6$. The position of the EC injection port and the available toroidal injection angle are shown in Fig. 4 with the magnetic field strength along the magnetic axis for different three $\varepsilon_{b}$ configurations (i.e. different field ripple ratio). (Figure.4)

The experimental results with this new launching system have revealed the $N_{\|}$dependence of EC driven current in different field ripple configurations ${ }^{[19]}$. The maximum EC driven current is attained at $N_{\|}=0.5$ when the EC power is deposited nearly at the ripple top, while the EC driven current is nearly zero independent of $N_{\|}$when the EC power is deposited near the ripple bottom. An important role of high-energy electrons is indicated from the strong correlation between EC current and ECE (electron cyclotron emission) signals. The detailed analysis of the 
experimental results including the $B$ and $N_{\|}$dependences is in progress with simulation using the TRAVIS code ${ }^{[20,21]}$.

\section{Resonance Position Dependence of Fast-Ion Energy Spectra Generated by ICRF}

In order to study the effect of the magnetic field ripple on fast-ion behavior and to optimize the ICRF heating condition in the three dimensional magnetic field configuration of the helical-axis heliotron, fast ion velocity distribution has been investigated using fast protons generated by ICRF minority heating in Heliotron $\mathrm{J}^{[22]}$. The cyclotron-resonance layer is located near the axis with a frequency of $19 \mathrm{MHz}$ in the STD configuration. Changing the frequency, the resonance layer can be shifted to the selected position (Fig. 5). (Figure.5)

The pitch angle $\psi_{\text {pitch }}$ dependences of ion energy spectra for two resonance positions, on-axis and HFS (inner-side) off-axis resonance, are investigated by using a CX-NPA ${ }^{[22]}$. For both the cases, the effective temperature of the minority protons $T_{\mathrm{eff}}^{\mathrm{H}^{+}}$, shows the pitch angle dependence and the peak of $T_{\mathrm{eff}}^{\mathrm{H}^{+}}$is observed at $\sim 120^{\circ}$ in the pitch angle. Higher $T_{\mathrm{eff}}^{\mathrm{H}^{+}}$is observed in the on-axis resonance case compared to the HFS resonance case. The number of fast ions is also large in the on-axis case compared to the HFS resonance case. However, the increase of the bulk ion temperature in the HFS resonance case is larger than that in the on-axis case. In order to understand these observations, three-dimensional wave analyses have been performed by using TASK/WM code ${ }^{[23]}$.

\section{Summary}

This paper reviewed recent progress of Heliotron J experiments from a viewpoint of plasma control to improve plasma performance in Heliotron $\mathrm{J}$.

1. The SMBI fueling is successfully applied to Heliotron J plasma. A supersonic $\mathrm{H}_{2}$-beam is effective to increase fueling efficiency and make a peaked profile. Local fueling with a short pulse by SMBI can increase the core plasma density avoiding the degradation due to the edge cooling. A large increment of plasma stored energy after a short pulse intense gas fueling from a conventional piezoelectric-valve system has been observed in NBI (or $\mathrm{NBI}+\mathrm{ECH}$ ) plasma. The physics under the observation would give us new insight into 
more preferable plasma operation conditions.

2. Second harmonic ECCD experiments have been performed. A focused Gaussian beam is injected with $-0.05 \leq N_{\|} \leq 0.6$. The experimental results show that the EC driven current is determined not only by $N_{\|}$but also by local magnetic field structure where the EC power is deposited. A large increase in ECE signals has been observed when the EC current was driven, indicating the important role of high-energy electrons on the ECCD. The detailed analysis of the experimental results on the $N_{\|}$and $B$ dependences is in progress with a ray tracing simulation using TRAVIS code.

3. Fast ion velocity distribution has been investigated using fast protons generated by ICRF minority heating. In the standard configuration in Heliotron J, the larger fast minority protons are observed in the on-axis resonance case than in the HFS resonance case. However, the increase of the bulk ion temperature in the HFS resonance case is larger.

\section{Acknowledgments}

The authors are grateful to the Heliotron J supporting group for their excellent arrangement of the experiments. One of the authors (T. M.) gives special thanks to Profs. L. Yao, Q.W. Yang and their colleagues in Southwestern Institute of Physics for kind instruction of SMBI experiments and fruitful discussions. This work is performed with the support and under the auspices of the JSPS-CAS Core University Program in the field of "Plasma and Nuclear Fusion", the Collaboration Program of the Laboratory for Complex Energy Processes, IAE, Kyoto University, the NIFS Collaborative Research Program (NIFS10KUHL030, etc.) and the NIFS/NINS project of Formation of International Network for Scientific Collaborations, as well as the Grant-in-Aid for Sci. Research, MEXT. 


\section{REFERENCES}

[1] SANO F, OBIKI T, WAKATANI M, et al. 2000, J. Plasma Fusion Research SERIES, 3: 26.

[2] OBIKI T, MMIZUUCHI T, NAGASAKI K, et al. 2001, Nuclear Fusion, 41: 833

[3] WAKATANI M, NAKAMURA Y, KONDO K, et al. 2000, Nuclear Fusion, 40: 569

[4] YOKOYAMA M, NAKAJIMA N, OKAMOTO M, et al. 2000, Nuclear Fusion, 40: 261

[5] MIZUUCHI T, SANO F, NAGASAKI K, et al. 2009, Study of Improved Confinement Modes in Heliotron J. The 17th IEA International Stellarator/Heliotron Workshop 2009, Princeton: I24, IEA, Paris

[6] MIZUUCHI T, KOBAYASHI S, YAMAMOTO S, et al. 2010, Contributions to Plasma Physics, 50: 639

[7] MINAMI T, OKAMURA S, AKIYAMA T, et al. 2008, Journal of Physics: Conference Series, 123: 012006

[8] YAO L. 2006, Chapter 3 in New Developments in Nuclear Fusion Research. Nova Science Publishers, Inc.: New York,.

[9] YAO L and BALDZUHN J. 2003, Plasma Science and Technology, 5: 1933

[10] GIRUZZI G, ABGRALL R, ALLEGRETTI L, et al. 2009, Nuclear Fusion, 49: 104010

[11] TAKENAGA H, OYAMA N, URANO H, et al. 2009, Nuclear Fusion, 49: 075012

[12] MIZUUCHI T, KOBAYASHI S, TAKEUCHI M, et al. 2010, Comparison between Supersonic Molecular Beam Injection and Conventional Gas-Puffing for Plasma Performance in Heliotron J. The19th PSI Conference, San Diego: P2-70, General Atomics, San Diego To be published in Journal of Nuclear Materials. (2010, http://dx.doi.org/10.1016/j.jnucmat.2010.10.027).

[13] MUKAI K, NAGASAKI K, ZHURAVLEV V, et al. 2010, Contribtions to Plasma Physic, 50: 646

[14] MIZUUCHI T, KOBAYASHI S, YAMAMOTO S, et al. 2010, Fueling Control for Improving Plasma Performance in Heliotron J. The 23rd IAEA Fusion Energy Conference, Deajeon: IAEA-CN-180/EXC/P8-11, IAEA, Vienna

[15] MIZUUCHI T, NAGATA H, OKADA H, et al. 2007, Nuclear Fusion, 47: 395

[16] MOTOJIMA G, NAGASAKI K, NOSAKU M, et al. 2007, Nuclear Fusion, 47: 1045 
[17] NAGASAKI K, MOTOJIMA G, KOBAYASHI S, et al. 2010, Nuclear Fusion, 50: 025003

[18] NAGASAKI K, SAKAMOTO K, MINAMI K, et al. 2010, Contributions to Plasma Physics, 50: 656

[19] NAGASAKI K, YAMAMOTO S, YOSHINO H, et al. 2010, Experimental Study of Second Harmonic ECCD in Heliotron J. The 23rd IAEA Fusion Energy Conference, Deajeon: IAEA-CN-180/EXW/P7-19, IAEA,Vienna

[20] MARUSHCHENKO N B, ERCKMANN V, HARTFUSS H J, et al. 2007, Plasma Fusion Research, 2: S1129.

[21] MARUSHCHENKO N B, MAASSBERG H and TURKIN Yu. 2008, Nuclear Fusion, 48: 054002

[22] OKADA H, KOBAYASHI S, KISHI S, et al. 2009, Heating Position Dependence of Energy Spectra of Fast Ions Generated by ICRF Heating in Heliotron J. The 17th IEA International Stellarator/Heliotron Workshop 2009, Princeton: P03-18, IEA, Paris

[23] FUKUYAMA A and AKUTSU T 2002, Kinetic Global Analysis of Alfven Eigenmodes in Toroidal Plasmas. The 19th IAEA Fusion Energy Conference 2002, Lyon: IAEA-CN-94/TH/P3-14, IAEA, Vienna 


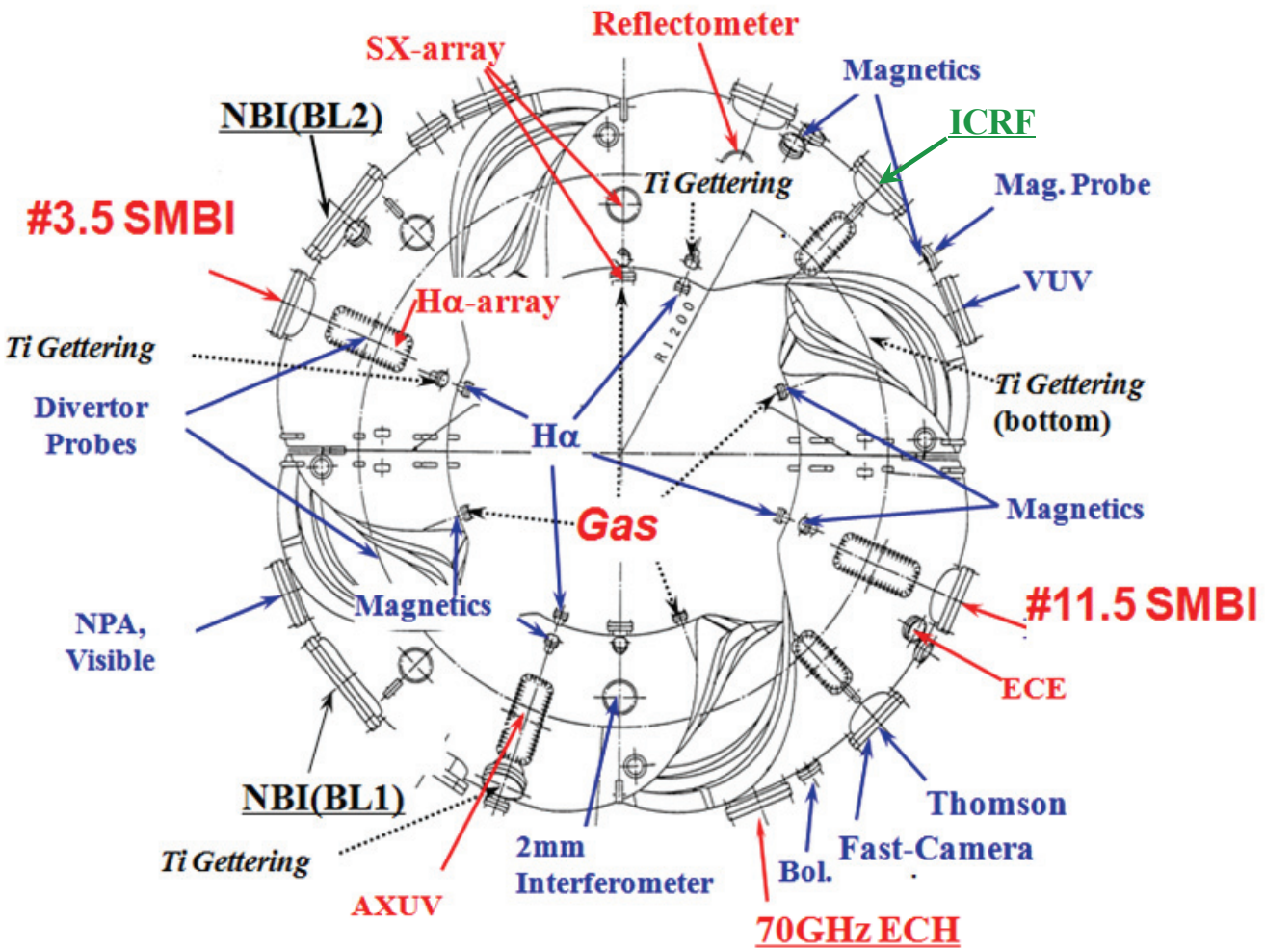

Figure 1 Experimental Set-up. A layout of main heating, fueling and diagnostic equipment. 
(a)
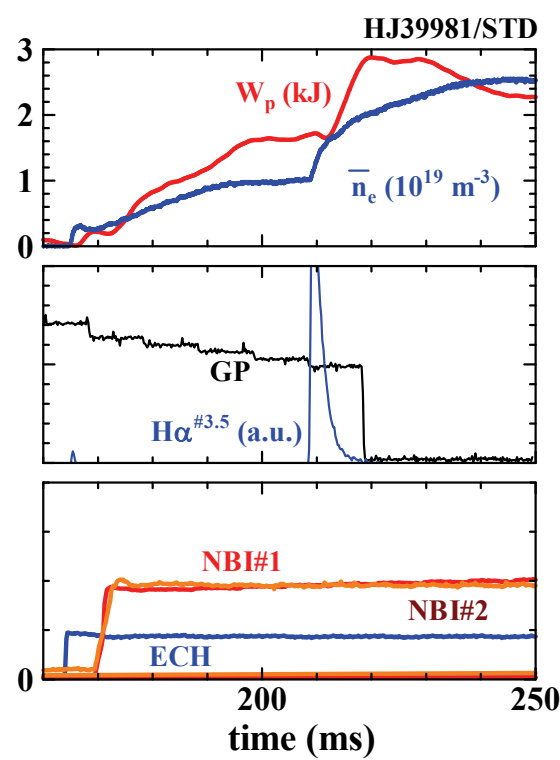

(b)
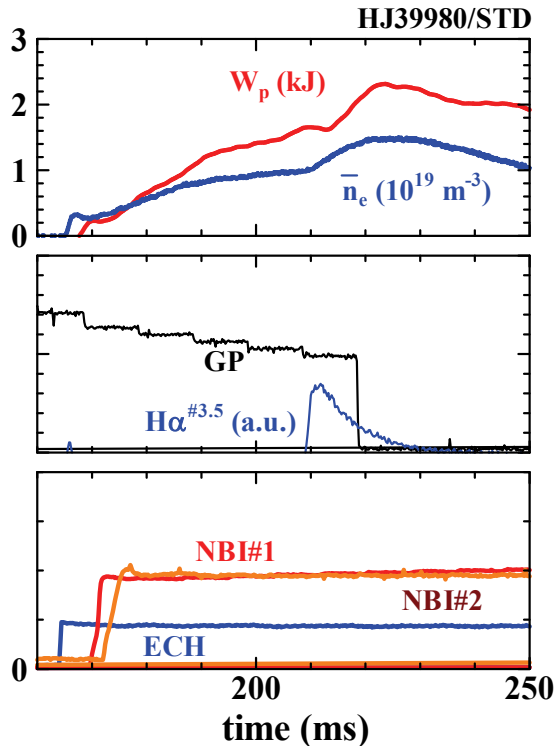

Figure 2 Time traces of the line-averaged density $\bar{n}_{\mathrm{e}}$, the stored energy $\mathrm{W}_{\mathrm{p}}$, the electric pulse for the gas-puff GP and $\mathrm{H \alpha}^{\# 3.5}$ for $\mathrm{ECH}(\sim 0.3 \mathrm{MW})+\mathrm{NBI}\left(\mathrm{P}_{\text {port-through }}{ }^{\text {total }} \sim 1 \mathrm{MW}\right)$ plasmas for two cases of open (a) and closed (b) conditions of the shutter in front of SMBI. 


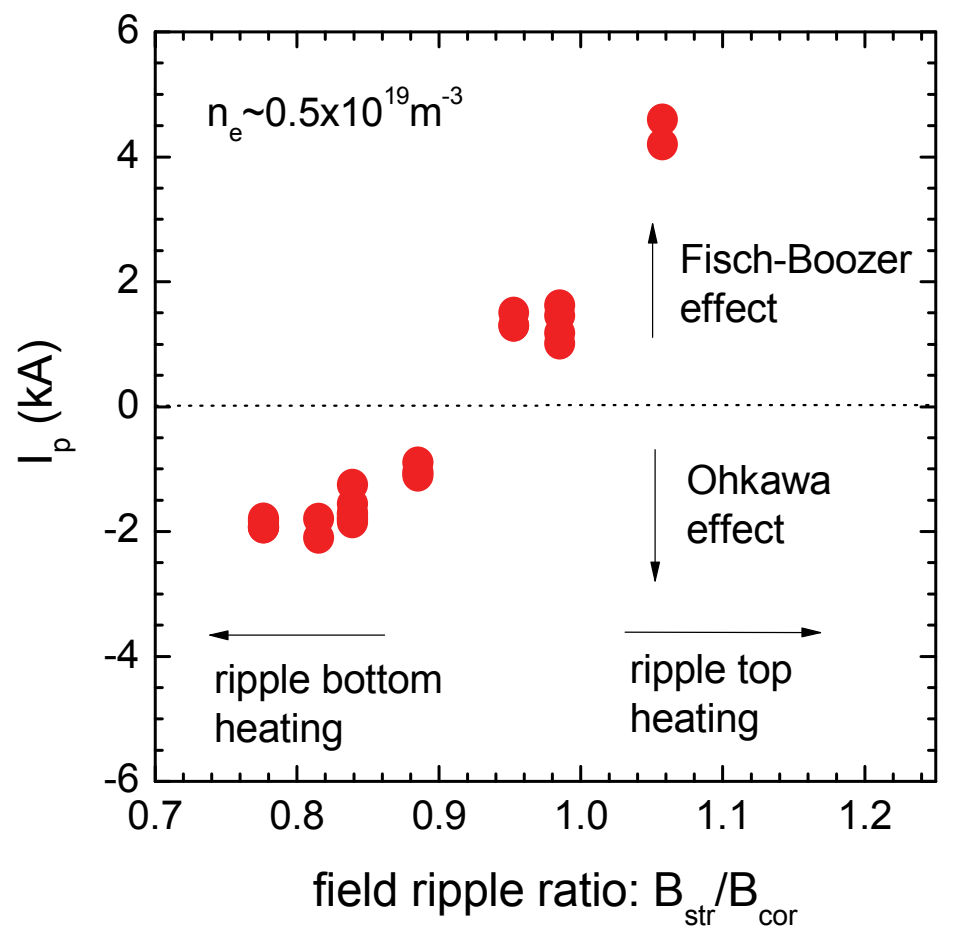

Figure 3. Dependence of measured toroidal current on magnetic field ripple. ${ }^{[17]}$ 


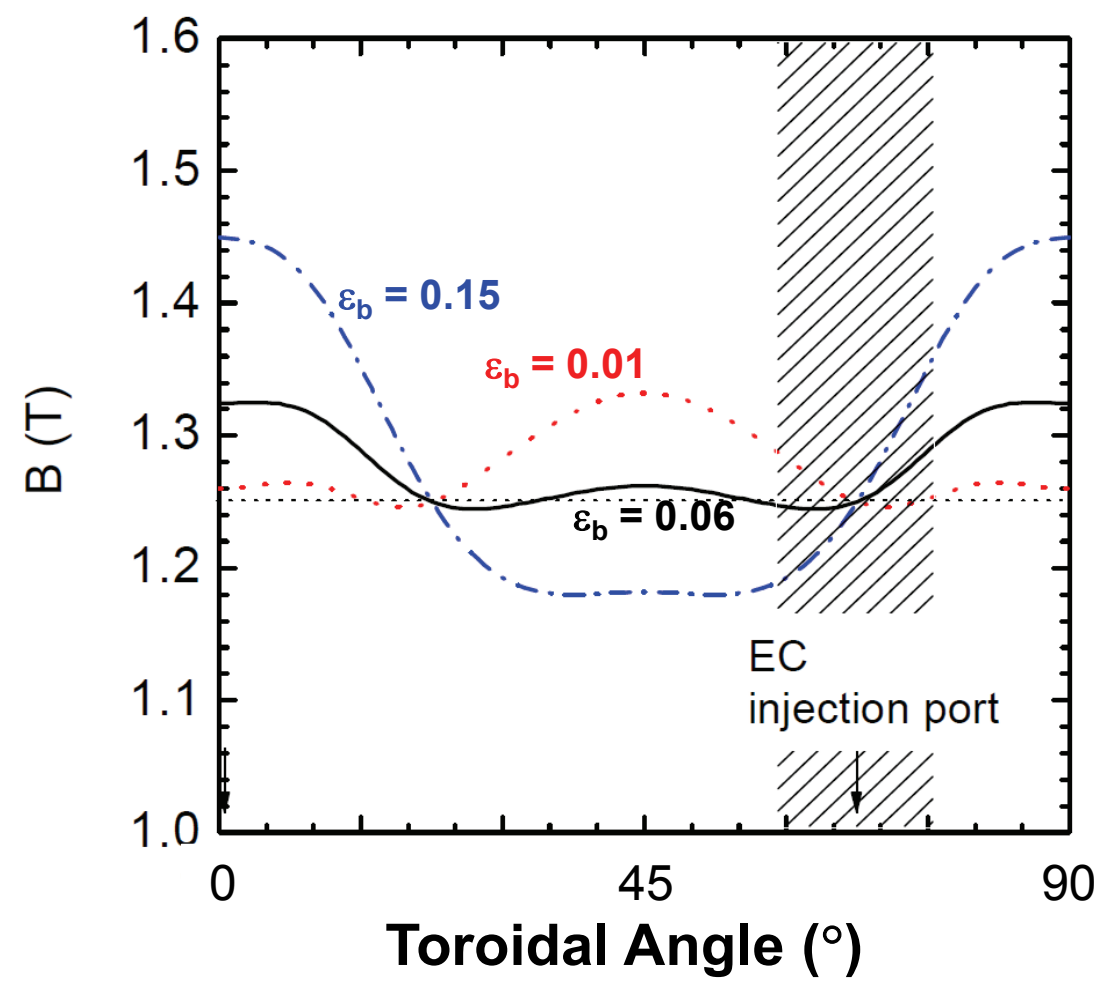

Figure 4. Magnetic field strength along the magnetic axis for different three $\varepsilon_{\mathrm{b}}$ configurations.

The shaded span denotes the available toroidal injection range. 

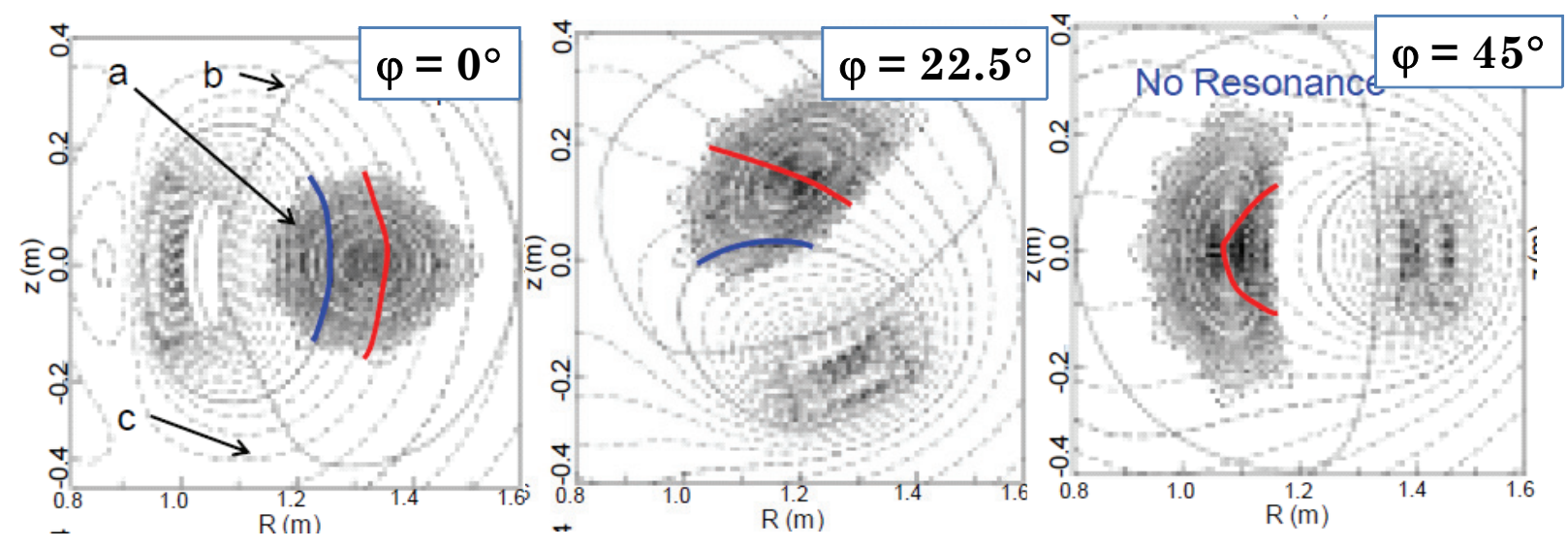

Fig. 5. The magnetic flux surfaces (a), vacuum chamber (b), mod-B surfaces (c), the fundamental cyclotron resonance layer of minority proton for $19 \mathrm{MHz}$ (red) and $23.2 \mathrm{MHz}$ (blue) at the various toroidal angle $(\varphi)$. The antennas are installed in the poloidal cross section at $\varphi=0^{\circ}$. Resonance layer for $19 \mathrm{MHz}$ is in the confinement region for any toroidal angle, while that for $23.2 \mathrm{MHz}$ is only in limited toroidal positions. 